\title{
So you want to publish Becoming a researcher
}

$\mathbf{N}$ ew librarians, experienced librarians, and those considering a change in career may want to start writing or researching for a variety of reasons, including meeting professional requirements. In this article, we share some tips for getting started, or perhaps inspiration for bringing old ideas back to life.

\section{Gathering your ideas and research}

Starting a project from scratch can feel intimidating, so consider whether you have current or past projects to build on, such as a thesis you have written, a paper from graduate school, or a project you're working on that may be relevant for others. Since librarianship is a practitioner field, questions of practice can generate ideas or help you make connections with areas you are already working on or are curious about. It may help to ask yourself the following:

- What bugs you?

- What do you think could be improved?

- What are unexamined assumptions in the field?

- What are pain points in your job, classroom, cataloging workflow, institution, etc.?

- What ethical issues or competing values are causing tensions in your job, classroom, institution, etc.?

Answers to questions like these are likely to be broad enough for exploration in an arti- cle or conference proposal, and to have room for both theoretical exploration and practical recommendations for libraries. Meanwhile, plan how you will capture ideas as they come to you, whether on paper or electronically. For example, one of our authors has a long commute and records voice memos of ideas and questions to return to later when time is set aside for research and writing.

For those without access to library and information science (LIS) databases, consider bookmarking websites for major journals and signing up for table of contents alerts via email. This can spark ideas and remind you to place interlibrary loan requests for articles of interest. Many authors are also placing paywalled work in their institutional repositories, publishing in open access LIS journals, or making their work searchable

Amanda Izenstark is reference and instructional design librarian at the University of Rhode Island University Libraries, email: amanda@uri.edu, Ann Agee is faculty director of collections and scholarly communication at San Jose State University, email: ann.agee@sjsu. edu, Holly Jackson is the student success librarian at Mansfield University of Pennsylvania's North Hall Library, email: hjackson@mansfield.edu, Anna Sandelli is head of teaching and learning programs at the University of Tennessee, Knoxville Libraries; email: asandell@utk.edu, and Linds West Roberts is education librarian and assistant professor at the University of ColoradoBoulder; email: robertlm@colorado.edu

(C) 2021 Amanda Izenstark, Ann Agee, Holly Jackson, Anna Sandelli, and Linds West Roberts 
through tools like Google Scholar's "All Versions" feature. It is also possible to reach out to the author directly for a copy or use ResearchGate or Academia.edu to request full-text access, though not all of these options respect copyright restrictions.

Depending on your plans and your institution, you may need to get a variety of approvals. Your supervisors can help determine what institutional support is available. If you are planning to use human subjects (e.g., your library users or students) as part of your research, consult your institution's Institutional Review Board (IRB).

While working with an IRB may seem daunting, it is also a way to get feedback on your research design and plans as you go forward, and ensures that your research is ethical, respecting the privacy of all involved. If you happen to be at an institution without an IRB, consider working with a colleague at an institution that does have an IRB, and follow the approval process there.

\section{Considering venues and your audience}

As you begin exploring venues and audiences for your work, consider these factors:

- Are there specific requirements for your tenure and/or promotion, if those are applicable?

- Does your campus value certain publications or conferences over others?

- Is the topic you want to write about necessary for your work or is it a passion project?

These will help you decide whether to pursue a more traditional peer-reviewed venue or publish via an open access medium. Both have benefits and drawbacks, so look at your needs and the needs of your institution before selecting a venue. In general, review the author guidelines for individual journals for exact requirements. If you're not sure what outlets to consider, ask your colleagues or friends in the field what they read.

When it comes to conferences, it's okay to start small. Local or state conferences can be great networking opportunities and often have better acceptance rates. These smaller presentations and projects can also lead to bigger projects and collaborations with other institutions. There are also an increasing number of virtual conferences and poster presentations. Check the call for proposals for the conference or reach out to one of the organizers for more details. Virtual conferences and local or state conferences also tend to be less costly, which can save you (or your institution) money while still giving you new opportunities for engaging in the field.

Along with journals and conferences, disciplinary, student, and/or institutional blogs and even student journals can be a starting point for your writing. These are less critical and provide a good platform for engaging with others regarding your research.

If your research is too long for a blog or journal article, consider contributing to a book, whether it's a chapter or authoring the entire book. To find calls for chapters, review listservs from ALA/ACRL or state/ regional library organizations. These listservs are also great for finding conference calls for proposals.

\section{Working with others}

Nearly any colleague you encounter at work, in meetings, at conferences, or even on social media or mailing lists is a potential collaborator. The recently launched LibParlor Classifieds are another way to find librarian-researchers with similar interests. While it may seem logistically easy to connect with local colleagues, geography doesn't need to be a hurdle. The authors of this article, for example, met while on an ACRL Instruction Section committee, and are distributed across the United States. Discussions during our committee meetings revealed 
shared interests and a potential collaboration. This led to meetings via Zoom and a folder in Google Docs, populated with ideas and eventually article drafts. Being open to opportunities is important as well. A recent study found that "The denser the research network is in terms of research collaborations, the higher the research output."

Online collaboration tools are available to assist at every point in the research and writing process, and many are free or have a free version available to support your work. For both preliminary conversations and later meetings, web conferencing software is helpful. Google, Microsoft, and Zoho offer productivity tools for collaborative writing and brainstorming. Zotero, Mendeley, RefWorks, and EndNote support the development of shared literature reviews.

If research involves surveys, Google Forms, Qualtrics, and SurveyMonkey offer options for sharing access to instruments. Finally, the Open Science Framework provides a platform for collaborating and gathering feedback on research during

\section{Consider these resources}

- The National Center for Faculty Development and Diversity Monday Motivator mailing list: https://www. facultydiversity.org/the-monday-motivator

- Institute for Research Design in Librarianship:https://library.lmu.edu/irdl/

- Library Juice Academy: https:// libraryjuiceacademy.com/

- The Librarian Parlor: https:// libparlor.com/

- LIS Publications Wiki http:// ischoolwikis.sjsu.edu/lispublications/

- Writing Your Journal Article in 12 Weeks by Wendy Laura Belcher

- How to Write a Lot: A Practical Guide to Productive Academic Writing by Paul J. Silva the process and in the time leading up to publication.

\section{Navigating fear, guilt, and imposter syndrome}

Once you have ideas, a venue, and collaborators, it may seem that the remaining pieces will naturally fall into place. For many, however, starting to write or to prepare a conference presentation elicits fear, guilt, and imposter syndrome that can make you question both your ideas and your abilities. While these challenges look different for everyone, acknowledging that they are valid challenges is often a helpful step in addressing them. Sharing your uncertainty and being open to talking about it may both help you and encourage others grappling with similar feelings.

Participating in learning opportunities, whether formally or informally, can help you move forward. If you have access to an institution that offers research methods or statistics classes, these can expand your skills, refresh your knowledge, build your network, or, equally importantly, remind you of expertise you already have. You may also wish to explore online options available through your library or library partnerships. A growing number of openaccess journals and e-books provide selfpaced options for learning, both about broad approaches and about specific research projects.

Engaging in community can also provide encouragement and inspiration throughout the research and publication process. Creating or participating in a writing or research interest group within or beyond your institution can alleviate fears about getting started, making time to write, managing deadlines, or navigating institution-specific requirements, such as for tenure. Group members don't need to work on the same project. In fact, a particularly beneficial experience for one author involved getting together with a group, sharing introductions and research inter- 
ests and projects, and spending the rest of the day working separately in a communal space, with occasional check-ins.

For solo librarians and those interested in virtual connections, online communities such as Twitter meetups or The Librarian Parlor blog are valuable ways of learning and connecting with others. These can also be a way of practicing self-compassion. For instance, one of our authors had an accountability writing buddy who regularly checked in about the progress of a journal article but also took time in every meeting to ask "How are you taking care of yourself?" and "What are you doing for fun outside of work?"

\section{Getting it written}

Productive writers do not wait for the muse. Instead, they make writing a habit, fitting in 30 minutes of work every weekday. Sometimes this time will be for brainstorming, sometimes for writing that awful first draft that reads like a bad translation of ancient Icelandic. Sometimes this time will be spent planning what to work on for the rest of the week. But it all begins by making the commitment and blocking out that time on your calendar as you would a meeting. Remember: you are always writing. Emails, reports, policies-writing for publication is simply a different structure.

Like any big project, break down your writing into manageable small tasks: review three sources for your literature review, write the first explanatory paragraph for your methodology section, or format that challenging chart. Each small piece will advance you to your goal. Do not ignore the emotions that writing creates in you. In addition to imposter syndrome, perfectionism can stand in your way-that nasty judge in your head who has no patience with ancient Icelandic. Show compassion to yourself as you would to a friend. Allow yourself to make mistakes and lock your internal judge in a convenient mental closet for your 30 minutes of writing.
For tenure-track librarians, writing and publishing is often required. For other librarians, however, this is not the case. If publishing is not mandated by your institution, carving out time to write becomes a challenge. One possibility is to have a working lunch, maybe with a writing support group made up of other interested librarians. Consider negotiating with your supervisor for dedicated writing time during your work week. Writing can be framed as outreach, part of obtaining grant funding, support for practitioners in the field, a way to enhance your institution's reputation, and simply as professional development. If persuasion fails and writing is a priority for you, it may have to happen on your own time.

If you are currently in a position without support for research or publication but hope to move into one, begin by writing for professional and trade journals, such as American Libraries or D-Lib Magazine. These less-intensive articles for practitioners can be used as evidence of a track record you can highlight when you apply for positions.

\section{Moving forward}

We hope the ideas offered will be starting points. Don't be afraid to reach out to others, initiating or joining conversations to develop your ideas. The same growth mindset we encourage in our students applies to us, too. It helps to focus on the research process rather than outcomes. To continue learning and growing as a researcher and writer, we recommend the resources in the sidebar.

\section{Note}

1. Marie R. Kennedy, Kristine R. Brancolini, and David P. Kennedy, "An Exploratory Study of Accomplished LibrarianResearchers," Evidence Based Library and Information Practice 15, no. 1 (2020): 179-217, https://journals.library.ualberta. ca/eblip/index.php/EBLIP/article /view/29655. z 